\title{
Role of Redox-, and Acid-Promote Dissolution Processes in Shaping Soil Water Chemistry of Reclaimed Mine Sites
}

\author{
AMIR HASS $^{1}$, JEFF SKOUSEN ${ }^{2}$
}

${ }^{1}$ Department of Biology, West Virginia State University, Institute, WV, USA, amirhass@wvstateu.edu

${ }^{2}$ Davis College, West Virginia University, Morgantown, WV, USA, Jeff.Skousen@mail.wvu.edu

Adequate reclamation of surface mine sites is essential for proper restoration of ecosystem services. Reclamation practices, especially on steep landscapes, commonly incorporate blasted rock fragments and/or weathered, nonconsolidated (saprolite), rock material with the salvaged native soil for use as 'topsoil substitute' during reclamation. Such practices dilute and reduce soil pools and capacity to properly regulate and control biogeochemical processes and outcomes. This study was set to evaluate the effect of reclamation practices on soil water chemistry and to elucidate the mechanisms involved in shaping solution composition.

Research sites in southern WV USA were constructed using different topsoil substitute material (weathered ['Brown'] or non-weathered ['Gray'] sandstone) and compaction treatments (compacted, deep-ripping, or loosely placed). Treatment areas were instrumented with shallow observation wells and zero-tension pan lysimeters 12 years after reclamation. Soil water was sampled weekly over a 3year period and analyzed for total metals content, ionic composition, alkalinity, and DOC, as well as in-situ measurements of $\mathrm{pH}$, TDS, DO, temperature, and ORP.

Solution composition fluctuated extensively withinseason in the Brown sites, and to a lesser extent in the Gray ones. Fluctuating by an order of magnitude, total soluble salts $\left(178-1762 \mu \mathrm{S} \mathrm{cm}^{-1}\right)$ were inversely related to Eh, peaking as $\mathrm{pH}$ shifted to circumneutral values, with carbonates, rather than sulfates being the dominant anion during events where regulatory thresholds were exceeded (i.e. TDS $>500 \mu \mathrm{S} \mathrm{cm}^{-}$ $\left.{ }^{1}\right)$. Drought conditions led to a sharp drop in soil moisture and $\mathrm{pH}$ (from 5.85 to 4.26), subsequently increasing solubility of elements of environmental concern (e.g. Al, Co, $\mathrm{Fe}, \mathrm{Mn}, \mathrm{Ni}, \mathrm{Zn}$ ).

The results are discussed with respect to soil development stage, the limited pools and role of terminal electron acceptors (e.g. Sulfates, free Fe/Mn oxyhydroxides), and the soil's overall ability to regulate and buffer changes in moisture, $\mathrm{pH}$, and redox potential amid increases in frequency and intensity of extreme weather events. 